\title{
Estado do conhecimento: cotas raciais nos serviços públicos para os cargos de docents
}

\author{
Status of knowledge: racial quotas in public services for teachers' positions
}

Vanessa Cristina Lourenço Casotti Ferreira da Palma ${ }^{1}$, Ariel de Jesus Silva ${ }^{2}$

\begin{abstract}
RESUMO
O artigo constitui parte de uma pesquisa de tese de doutorado que foi defendida em 2019. Tem por objetivo realizar um levantamento de dissertações e teses que tenha como foco as reservas vagas para negros em concurso público federal para o cargo de docentes. A metodologia utilizada de caráter exploratório bibliográfico em trinta dissertações e cinco teses encontradas no banco de dados da Capes e Ibict entre os anos de 2010 a 2016 apontaram a ausência de dissertação e teses relacionadas com o tema cotas raciais para concurso público federal. Das trinta dissertações e cinco teses consideradas nas coletas de dados se restringiram apenas a leitura dos resumos observou-se que a maioria encontrava dentro da área do conhecimento em Educação e Direito cujas defesas se concentraram no ano de 2011 e 2012. Como resultado que ausência de teses e dissertações durante o período levantado (2010 a 2016) se deu em razão da lei ter sido publicada em junho de 2014, portanto uma temática atual.
\end{abstract}

Palavras-chave: Magistério federal; Concurso público; Cotas raciais.

\section{ABSTRACT}

The article is part of a doctoral thesis research that was defended in 2019. Its purpose is to carry out a survey of dissertations and theses that focuses on the vacant reserves for blacks in federal public examinations for the position of professors. The bibliographical exploratory methodology used in thirty dissertations and five theses found in the Capes and Ibict database between the years 2010 to 2016 pointed to the absence of dissertations and theses related to the theme of racial quotas for federal public examination. Of the thirty dissertations and five theses considered in the data collection, only the reading of the abstracts was restricted, it was observed that most were within the area of knowledge in Education and Law, whose defenses were concentrated in the year 2011 and 2012. As a result, the absence of theses and dissertations during the period surveyed (2010 to 2016) were due to the fact that the law was published in June 2014, therefore a current theme.

Keywords: Federal Magisterium; Public tender; Racial quotas

\footnotetext{
${ }^{1}$ Universidade Federal de Mato Grosso do Sul, Campus de Três Lagoas, e-mail vanessacasotti@hotmail.com

${ }^{2}$ UFMS/CPTL, e-mail arieljs@ live.com
} 


\section{INTRODUÇÃO}

O estudo do estado do conhecimento sobre o tema: "Cotas Raciais nos serviços públicos para os cargos de docents”, tem por finalidade examinar a Lei n. ${ }^{\circ} 12.990 / 2014$, referente a cotas raciais para os concursos públicos para professores de universidades federais.

Esse estado do conhecimento foi realizado e concluído para embasar a tese de doutorado concluído em 2019. Os descritivos utilizados na pesquisa foram: ações afirmativas; cotas raciais; concurso público/mercado de trabalho. A metodologia utilizada de caráter exploratório bibliográfico em trinta dissertações e cinco teses encontradas no banco de dados da Capes e Ibict entre os anos de 2010 a 2016. Das trinta dissertações consideradas nas coletas de dados se restringiram apenas a leitura dos resumos observou-se que a maioria encontrava dentro da área do conhecimento em Educação e Direito cujas defesas se concentraram no ano de 2011 e 2012. Já as cinco teses uma foi lida integralmente. A área do conhecimento relacionada com temas das dissertações, teses foi Educação e Direito e com melhor assiduidade outras áreas afins como Psicologia, Sociologia, Administração entre outras.

Para um melhor entendimento sobre a pesquisa o artigo foi divido em dois itens no primeiro descreve sobre a Lei 12.990 de 2014 sobre as políticas de cotas nos concursos públicos com base no Estatuto da Igualdade Racial (Lei n.12288/2010), bem como apresenta os índices estatísticos da ausência de pessoas negras nos serviços públicos federais. No segundo momento faz um levantamento de teses e dissertações com a finalidade de levantar assuntos que abordam a Lei de Cotas Raciais nos serviços públicos federais para os cargos de docentes nas universidades públicas brasileiras, como uma forma de inclusão da população negra no serviço público federal.

\section{CONTEXTUALIZAÇÃO DA LEI N. 12.990 DE 2014 SOBRE COTAS RACIAIS EM CONCURSOS PÚBLICOS FEDERAIS PARA DOCENTES}

Para eliminação das desigualdades e visando a garantia de inserção da população negra no serviço público, impulsionada pela luta constante do Movimento Negro no Brasil, foi instituída a Lei n ${ }^{\circ} 12.288 / 2010$, o Estatuto da Igualdade Racial, que dispõe em seu artigo $1^{\circ}$ e incisos:

Art. 1 Esta Lei institui o Estatuto da Igualdade Racial, destinado a garantir à população negra a efetivação da igualdade de oportunidades, 
a defesa dos direitos étnicos individuais, coletivos e difusos e o combate à discriminação e às demais formas de intolerância étnica.

Parágrafo único. Para efeito deste Estatuto, considera-se:

I - discriminação racial ou étnico-racial: toda distinção, exclusão, restrição ou preferência baseada em raça, cor, descendência ou origem nacional ou étnica que tenha por objeto anular ou restringir o reconhecimento, gozo ou exercício, em igualdade de condições, de direitos humanos e liberdades fundamentais nos campos político, econômico, social, cultural ou em qualquer outro campo da vida pública ou privada;

II - desigualdade racial: toda situação injustificada de diferenciação de acesso e fruição de bens, serviços e oportunidades, nas esferas pública e privada, em virtude de raça, cor, descendência ou origem nacional ou étnica;

III - desigualdade de gênero e raça: assimetria existente no âmbito da sociedade que acentua a distância social entre mulheres negras e os demais segmentos sociais;

IV - população negra: o conjunto de pessoas que se autodeclaram pretas e pardas, conforme o quesito cor ou raça usado pela Fundação Instituto Brasileiro de Geografia e Estatística (IBGE), ou que adotam auto definição análoga;

V - políticas públicas: as ações, iniciativas e programas adotados pelo Estado no cumprimento de suas atribuições institucionais;

VI - ações afirmativas: os programas e medidas especiais adotados pelo Estado e pela iniciativa privada para a correção das desigualdades raciais e para a promoção da igualdade de oportunidades (BRASIL, 2010. Grifo nosso).

Observa-se, pelo inciso VI, a possibilidade de o Estado promover ações específicas para promoção da igualdade de oportunidades. Em seu artigo 38, o Estatuto estabelece a reponsabilidade do Estado em garantir esse acesso.

Art. 38. A implementação de políticas voltadas para a inclusão da população negra no mercado de trabalho será de responsabilidade do poder público, observando-se:

I - o instituído neste Estatuto;

II - os compromissos assumidos pelo Brasil ao ratificar a Convenção Internacional sobre a Eliminação de Todas as Formas de Discriminação Racial, de 1965;

III - os compromissos assumidos pelo Brasil ao ratificar a Convenção no 111, de 1958, da Organização Internacional do Trabalho (OIT), que trata da discriminação no emprego e na profissão;

IV - os demais compromissos formalmente assumidos pelo Brasil perante a comunidade internacional (BRASIL, 2010). 
O governo deverá, portanto, assegurar a igualdade de oportunidades no mercado de trabalho para a população negra, conforme descrito no artigo 39 do Estatuto da Igualdade Racial.

Art. 39. O poder público promoverá ações que assegurem a igualdade de oportunidades no mercado de trabalho para a população negra, inclusive mediante a implementação de medidas visando à promoção da igualdade nas contratações do setor público e o incentivo à adoção de medidas similares nas empresas e organizações privadas.

$\S 1^{\circ}$ A igualdade de oportunidades será lograda mediante a adoção de políticas e programas de formação profissional, de emprego e de geração de renda voltados para a população negra (BRASIL, 2010).

A medida tem sua necessidade evidenciada pelos dados referentes à condição social: pesquisa do IPEA de 2009, por exemplo, constata que, entre o $1 \%$ mais ricos do país, $82,5 \%$ são brancos, enquanto $16 \%$ são pretos e pardos. Entre os $10 \%$ mais pobres, 25,4\% são brancos enquanto 74,2\% são pretos e pardos (IPEA, 2009).

Esses dados levam à conclusão de que, não obstante tenha o poder público promovido o acesso de negros ao ensino superior via cotas em provas de ingresso, tal medida ainda não apresentou eficácia no que concerne às possibilidades de acesso da população negra aos cargos públicos, bem como à sua participação na aquisição de meios de vida condignos com sua nova realidade. Não basta o porte de diploma de nível superior; há que se possibilitar a igualdade de condições de ingresso no mercado de trabalho e na esfera pública.

Tais ações afirmativas corroboram a ideia de que a igualdade se faz mediante a superação de obstáculos passíveis de colocar em risco sua eficácia, entraves referentes não somente às condições pessoais, como no caso de pessoas com deficiência, mas também histórico-sociais, considerando a herança de preconceito e restrições das condições mínimas de sobrevivência impostas aos negros e seus descendentes em nosso país.

A Lei de Cotas (12.990/2014) dispõe a reserva para pretos e pardos de 20\% (vinte por cento) das vagas oferecidas nos concursos públicos para provimento de cargos e empregos públicos efetivos realizados no âmbito da administração pública direta federal, e da administração indireta federal, tais como: autarquias, empresas públicas, fundações públicas e sociedades de economia mista (BRASIL, 2014), que dispõe no seu artigo 1: 
Art. $1^{\circ}$ Ficam reservadas aos negros $20 \%$ (vinte por cento) das vagas oferecidas nos concursos públicos para provimento de cargos efetivos e empregos públicos no âmbito da administração pública federal, das autarquias, das fundações públicas, das empresas públicas e das sociedades de economia mista controladas pela União, na forma desta Lei (BRASIL, 2014).

Apesar de devidamente publicada a Lei de Cotas Raciais em junho de 2014 seguindo todos os tramites legais quanto sua validade e existência a mesma carece de efetividade, devidos a vários fatores que estão limitando sua aplicação.

Por ser uma política afirmativa de inclusão de negros nos serviços públicos federais, tendo como prazo de 10 (dez) anos de vigência a Lei $\mathrm{n}^{\circ}$ 12.990/2014 tem como principal objetivo promover a inserção do grupo discriminado por motivo de raça/etnia pelo domínio de uma elite política e econômica (BRASIL, 2014).

Segundo o IBGE a população negra atingiu 53\% (cinquenta e três por cento). De acordo com o Sistema Integrado de Administração de Recursos Humanos (Siape) 32,3\% dos servidores são pretos e pardos. Comparando a população geral do país há uma grande diferença entre o percentual de pretos e pardos nos serviços públicos federais.

Essas informações são complementadas por dados disponibilizados pelo Ministério de Planejamento no Painel Estatístico de Pessoal (PEP, 2017). Segundo esses dados, o cargo de professor titular encontra-se entre os cinco maiores salários do Poder Executivo. No Sistema Integrado de Administração de Recursos Humanos (SIAPE, 2014) também se verifica que, em relação aos servidores ativos e efetivos do Poder Executivo Federais, de acordo com o nível de escolaridade exigido para o cargo, com base na raça ou cor, há uma disparidade no quantitativo entre servidores negros e não negros.

Segundo SIAPE, em 2014, dos cargos que exigem nível superior, 61,1\% eram preenchidos por pessoas brancas. Já os cargos de níveis auxiliares e administrativos eram preenchidos, em sua maioria, por negros, sendo $6,4 \%$ de servidores pretos e $44,3 \%$ de servidores pardos, perfazendo um total de 49,7\% (SIAPE, 2014). Na figura abaixo, ficam evidentes as diferenças de oportunidades entre negros e brancos no serviço público federal, visto que os servidores do executivo federal são, predominantemente, de cor branca, num total de $51,7 \%$. 
Imagem 1: Servidor segundo a cor/raça.

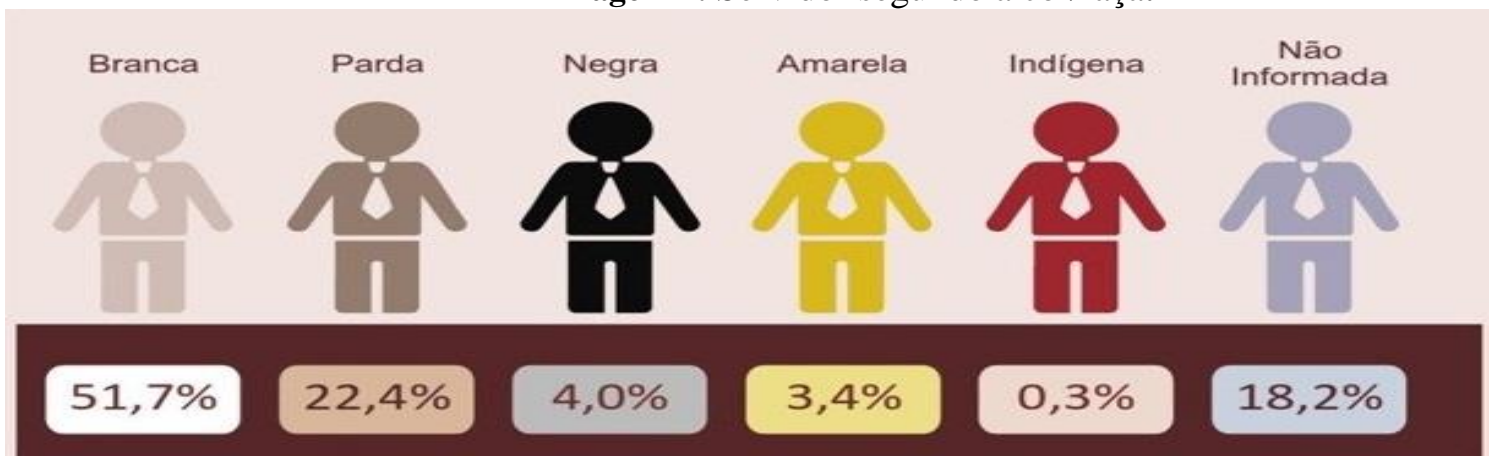

Fonte: Siape (Extrator de dados) /MP, junho de 2014.

Deste modo a lei de cotas que reserva as vagas para negros em concursos públicos federais é uma política compensatória para garantir igualdade de oportunidades da população negra nos concursos públicos, por esse motivo há a necessidade de ser realizada pesquisas que envolvem essa temática desta maneira foi realizada o estado de conhecimento visando levantar pesquisas (dissertações e teses) que enfoquem a inclusão de negros e negras nos serviços públicos federais.

\section{COLETAS DE DADOS DE DISSERTAÇÕES, TESES E ÁREA DO CONHECIMENTO}

A insuficiência de produção acadêmica que envolve a Lei $\mathrm{n}^{\circ}$ 12.990/2014 foi demonstrada pelo estado do conhecimento que iniciou-se a partir do arrolamento de temas que dialogassem com o objeto de pesquisa, a fim de recolher informações prévias sobre o campo de interesse.

Para tanto, foi utilizada a pesquisa bibliográfica com vistas a mapear pesquisas já tornadas públicas relacionadas com o tema abordado nesse estudo: sites de dissertações e teses. Nessa investigação, foram usados três descritores: ações afirmativas/ políticas públicas; cotas raciais/inclusão e concursos públicos/mercado de trabalho.

A primeira base de dados pesquisa foi o inventário de teses e de dissertações, isto é, o banco de dados da Coordenação de Aperfeiçoamento de Pessoal de Nível Superior (CAPES). A segunda foi o Instituto Brasileiro de Informação em Ciência e Tecnologia (IBICT), ambas observadas em um recorte temporal do ano de 2010 até 2016.

No levantamento realizado com trinta dissertações e cinco teses, foram encontrados com maior frequência temas relacionados com os descritores: ações 
afirmativas e cotas raciais. Em relação ao descritor concurso público/mercado de trabalho, observou-se uma menor incidência em relação à produção e à defesas de teses e de dissertações. As áreas do conhecimento que mais se sobressaíram em relação aos temas das dissertações e das teses foram as de Educação e Direito. Todavia, as de menor incidência vinculam-se às áreas da Psicologia, da Sociologia, da Administração, entre outras.

Das trinta dissertações consideradas nas coletas de dados, optou-se pelo procedimento metodológico de analisar apenas os resumos, visto que são um panorama das informações tratadas no todo de cada trabalho, por apresentarem objetivos (gerais e específicos), hipótese, base teórica e resultados obtidos. Nesse processo, observou-se que a maioria se encontrava nas áreas do conhecimento em Educação e Direito e foram defendidas entre os anos de 2011 e 2012 (conforme quadros de referências). Quanto às cinco teses de doutorado selecionadas para análise, também se concentraram no ano de 2011 e 2012 e apresentaram maior relação com a área da Educação. Para melhor compreensão, a tabela a seguir apresenta a relação das pesquisas selecionadas, considerando ano de defesa e área de concentração.

Quadro 1 - Área do conhecimento, ano e quantitativos de dissertações teses.

\begin{tabular}{|l|c|l|}
\hline \multicolumn{1}{|c|}{ ÁREA } & $\begin{array}{c}\text { ANO DE } \\
\text { DEFESA }\end{array}$ & $\begin{array}{c}\text { QUANTITATIVO } \\
\text { DE TRABALHO POR ANO: } \\
\text { DISSERTAÇÕES E TESES }\end{array}$ \\
\hline EDUCAÇÃO & 2011 & 8 DISSERTAÇÕES - 2 TESES \\
& 2012 & 6 DISSERTAÇÕES - 1 TESE \\
\hline DIREITO & 2011 & 5 DISSERTAÇÕES \\
& 2012 & 3 DISSERTAÇÕES \\
& 2014 & 1 DISSERTAÇÃO \\
\hline SOCIOLOGIA & 2011 & 1 DISSERTAÇÃO \\
& 2012 & 1 DISSERTAÇÃO \\
\hline
\end{tabular}




\begin{tabular}{|l|c|l|}
\hline LETRAS & 2012 & 1 DISSERTAÇÃO \\
\hline $\begin{array}{l}\text { INCLUSÃO SOCIAL } \\
\text { ACESSIBILIDADE }\end{array}$ & 2011 & 1 DISSERTAÇÃO \\
\hline PSICOLOGIA & 2011 & 1 DISSERTAÇÃO \\
\hline CIÊNCIAS SOCIAIS & 2010 & \\
\hline
\end{tabular}

Fonte: Elaborada pelos autores, com dados da CAPES e do IBICT.

Das dissertações analisadas, na área de Educação, o tema mais saliente foi o de “políticas de cotas nas Universidades Públicas", relacionado à categoria ações afirmativas/políticas públicas. Os trabalhos que assinalavam a avaliação dessas políticas como forma de inclusão serão descritos a seguir.

Um desses trabalhos é a dissertação "Avaliação da Política de Cotas da UEPG: Desvelando o Direito à Igualdade e à Diferença”, defendida em 01/02/2012, de Andreliza Cristina de Souza. O objetivo foi a realização de uma avaliação da efetividade da política de cotas quanto ao acesso ao ensino superior para estudantes negros advindos de escolas públicas. Amparada em uma metodologia de pesquisa baseada em análises qualitativas, em questionários, em entrevistas e na fundamentação teórica de Bordieu (2004, 2009, 2010), Passeron (2008), Bobbio (2000), Mateuccie (2008) e Pasquino (2008), concluiuse que a Política de Cotas da UEPG é efetiva por três aspectos: no primeiro é a democratização do acesso dos estudantes excluídos do ensino superior. No outro aspecto, nota-se a elevação dos índices de ingresso e da diminuição da evasão de estudantes. Por fim, apontou-se que o ingresso por meio das cotas não acarreta baixo rendimento (SOUZA, 2012).

Outra produção encontrada foi a dissertação “Cotas para Estudantes Negros do Instituto Federal de Santa Catarina - Campus São José”, defendida em 01/06/2012, de autoria de Mariangela de Mattos. O foco da autora centrou-se nas ações afirmativas no ensino superior, com o objetivo de verificar o significado do ingresso via cotas nos cursos superiores. A autora norteou-se por uma abordagem teórica fundamentada na análise do processo de escravidão e na construção do mito de democracia racial gerador das desigualdades educacionais existentes entre negros e brancos. Por esse processo analítico, Mattos (2012) pode concluir por meio de relatos como foi implementada a política de cotas no Instituito Federal de Santa Catarina. 
Na dissertação de Mario Marcio Negrão, intitulada "Políticas Educacionais e o acesso do negro na Educação Superior no Governo Lula. Além das Cotas?”, defendida em 01/10/2011, o autor tem como objetivo apresentar quais foram as políticas da diversidade, instituídas durante o governo Lula, capazes de nortear políticas públicas educacionais fundamentadas na inclusão. Como demostrou Negrão (2011), apesar dos avanços que resultaram dos princípios, projetos e ações com parcerias na CONAE, SECAD e SEPPIR, entre outros, ainda há uma fragmentação de esforços e carências de princípios unificantes. Na conclusão, o autor demostrou que as injustiças sociais não estão nas cotas.

Na sequência, debruça-se sobre a pesquisa de Katia Cristina Noroes, denominada “Cotas Raciais ou Sociais? Trajetória, Percalços e Conquistas na Implementação de ações afirmativas no ensino superior", defendida em 2011. O objetivo consiste em investigar as políticas de cotas para institucionalização de programas para acesso aos concursos de graduação, seja por meio de cotas raciais ou sociais. Esta investigação apontou à seguinte conclusão: houve maior aceitação do argumento social em contrapartida ao racial. "Possibilitou que grande parte das IES reestruturasse seus mecanismos de ingresso e repensasse o perfil de estudante atendido" (NOROES, 2011).

Na dissertação de Luciane Bello, "Política de ações afirmativas na UFRGS: O processo de resiliência na trajetória de vida de estudante cotistas negros com bom desempenho acadêmico", defendida em 2011, também na área de Educação, teve como objetivo analisar o processo de resiliência em estudantes cotistas de escolas públicas autodeclarados negros com bom desempenho acadêmico, que ingressaram pelo sistema de reserva de vagas aprovado na Universidade Federal do Rio Grande do Sul em 2008. A autora concluiu que as instituições como um todo devem se reformular quanto ao oferecimento de cursos noturnos, da súmula de disciplinas, do material didático, da assistência estudantil" (BELLO, 2011).

Nessa pesquisa bibliográfica, também foi possível encontrar a dissertação "Universidade Pública e Inclusão Social: As cotas para autodeclarados negros na Universidade Federal do Rio Grande do Sul” de Maria Cristina LunardiKern, produto de seu mestrado profissional de Inclusão social e acessibilidade. O objetivo foi observar como as ações afirmativas funcionam enquanto medidas especiais, temporárias ou não, implementadas pelo Estado e por setores da sociedade civil, que visam corrigir 
desigualdades acumuladas ao longo de muitos anos, sejam elas raciais, de gênero, religiosas, étnicas, entre outras, e garantir a igualdade de oportunidades e de tratamento.

Além dessas pesquisas pertencentes à área educacional, foi possível verificar dissertações vinculadas à temática oriundas de outras áreas, principalmente, a jurídica. $\mathrm{O}$ processo analítico permitiu constatar em todas uma grande preocupação com questões relativas à igualdade racial e à inclusão.

Dentre esses trabalhos originários das demais áreas afins à educação, está a dissertação de Jussara Schittler dos Santos Wandscheer, intitulada "O princípio da igualdade face ao sistema de cotas nas universidades públicas" defendida em 2011, proveniente da área do Direito. O objetivo pautou-se na análise sobre o conceito de isonomia e sua evolução com a finalidade de buscar fornecer subsídios para implementar sistema de cotas nas universidades brasileiras (WANDSCHEER, 2011).

Há, ainda, a dissertação de Thays Oliveira de Britto, produzida durante o seu mestrado acadêmico em Direito, intitulada: “Ações afirmativas: Cotas para negros nas Universidades Públicas”, defendida no ano de 2011. Britto (2011) objetivou identificar qual é a verdadeira causa da desigualdade educacional entre brancos e negros e apontar se o preconceito existente no país é capaz de impedir a ascensão social dos negros.

Por meio de um traçado metodológico baseado em pesquisa bibliográfica e no levantamento de dados estatísticos de órgãos oficiais, como o Instituto Brasileiro de Geografia e Estatística (IBGE), a análise dos números da exclusão social no país, teve como resultado ainda a presença do racismo no Brasil. Todavia, esse fator não seria elemento capaz de impedir a ascensão social do negro. Outrossim, as cotas raciais e sociais devem caminhar juntas no combate à pobreza e à desigualdade social.

Por fim, há também a dissertação, na área de Educação, de Marcelo Barbosa dos Santos, que trabalhou a temática "Mérito e Racismo: Tudo junto e misturado", defendida em 2011. O autor (SANTOS, 2011) teve como objetivo analisar "de maneira crítica, a vinculação ideológica do mérito e racismo, demonstrando como a união dessas ideologias, no caso brasileiro, é instrumento eficaz para a manutenção da desigualdade racial no Brasil". Pôde concluir a existência de uma meritocracia de perfil racista defendida por uma elite branca sob seu domínio como espaços importantes na estrutura de poder e de perpetuação de seus privilégios. Em relação ao terceiro descritor, "mercado 
de trabalho/concursos públicos", as dissertações levantadas foram mais restritas quanto à temática desenvolvida. As discussões focalizaram-se na inserção no mercado de trabalho para pessoas com deficiência.

Na área do Direito, é possível citar a dissertação de Renato Neves de Oliveira, intitulada "Ações Afirmativas no Mercado de Trabalho: um estudo sobre a concretização do direito fundamental ao trabalho no Brasil”, defendida em 2012, e a dissertação de Ana Silvia MarcattoBegalli: "A efetividade do direito ao trabalho da pessoa com deficiência no Brasil", defendida também em 2012. Ambas enfocam a inserção de pessoas com deficiência no mercado de trabalho e os benefícios dessa contratação. Tais pesquisas contribuem indiretamente com esta pesquisa de doutoramento por focalizarem o setor trabalhista e discutirem a condição de indivíduos em situação de exclusão.

Além desses estudos já citados contempla-se a dissertação defendida em 2011, no curso de Psicologia, intitulada: "A inclusão do negro na universidade e no trabalho", de autoria de Daniela Silva Conceição Almeida e Elisabete Figueroa dos Santos. O objetivo foi avaliar o mercado de trabalho e as políticas afirmativas para inserção de deficiente com base na Lei n. 8.2013/11.

A análise dessas pesquisas de mestrado, bem como de seus respectivos resumos, constatou que o descritor "ações afirmativas/políticas públicas" delineia-se como o mais frequente. Em contrapartida, foi possível observar que o descritor "concurso público/mercado de trabalho" configurou-se como o menos incidente. Com a finalidade de facilitar a compreensão da análise, segue a tabela abaixo:

Quadro 2 - Dissertações: Temas, quantidade e área do conhecimento.

\begin{tabular}{|l|c|l|}
\hline \multicolumn{1}{|c|}{ TEMAS } & QUANTIDADE & ÁREA DO CONHECIMENTO \\
\hline $\begin{array}{l}\text { Ações afirmativas/políticas } \\
\text { públicas }\end{array}$ & 10 & Educação \\
& 04 & Direito \\
& 01 & Sociologia \\
& 01 & Ciências Sociais \\
& 01 & Letras \\
\hline & 03 & Direito \\
Cotas raciais & 04 & Educação \\
\hline
\end{tabular}




\begin{tabular}{|l|l|l|}
\hline Igualdade/inclusão/racismo & 01 & Inclusão Social \\
& 01 & e Acessibilidade \\
Sociologia \\
Administração \\
\hline $\begin{array}{l}\text { Concurso Público/mercado } \\
\text { de Trabalho }\end{array}$ & 01 & Direito \\
\hline
\end{tabular}

Fonte: Elaborada pelos autores, com dados da CAPES e do IBICT.

A partir do mesmo foco analítico, após a leitura dos cinco resumos pertencentes às teses de doutorado, foi averiguado que três delas apresentavam relação com a categoria/descritivo: igualdade, inclusão e racismo, a saber: 1) A tese de Daniela Frida Drelich Valentim, com o título "Ex-Aluno Negros Cotistas da UERJ: Os desacreditados e o sucesso acadêmico", defendida em 2012; 2) A tese "Universidade Zumbi dos Palmares: uma proposta alternativa de inclusão do negro no ensino superior", do autor José Vicente, defendida em 2012; 3) A tese de Waleria Furtado Pereira, "Prática de Inclusão na Universidade: representações de Professores e Estudantes", defendida em 2011. Dessas três, a última foi lida integralmente, pois tem ligação parcial com a temática desenvolvida neste trabalho.

Pereira (2011) discorre sobre a representação do professor negro e a inclusão na universidade e se vale de Pierre Bourdieu na sua fundamentação teórica, especificamente da noção de habitus dos professores e alunos, para fazer uma relação com os contextos midiáticos e a sua influência no que concerne à prática da inclusão no ambiente acadêmico (2011, p. 95). A autora buscou problematizar a importância da formação do docente para atuar numa sociedade plural. Nesse caminho de preparar o professor para uma atuação plural capaz de lidar com as diferenças, o objetivo da pesquisa centrou-se na inserção da universidade neste contexto inclusivo, uma vez que as diferenças habitam todos os níveis educacionais.

Outra tese analisada vincula-se ao descritor "ações afirmativas/políticas públicas" e intitula-se "O descentramento e a desracialização do Nacional: Estado, relações étnicoraciais e ações afirmativas no Brasil", foi defendida em 2014 e é de autoria de Priscila Martins Medeiros. Objetivo desse trabalho centrou-se em perceber as rupturas e 
transformações conceituais e ideológicas nos estados diante das lutas antirracistas e das conquistas de direitos.

A última tese analisada, de autoria de Marcilene Garcia de Souza, intitulada: "Ações afirmativas e inclusão de negros por cotas raciais nos serviços públicos do Paraná", foi lida integralmente, por possuir relação com o tema pesquisado. Essa pesquisa, defendida em 19 de novembro de 2010, ligada ao programa de Pós-Graduação de Ciências Sociais - FCLAR, teve como foco a análise da Lei n. ${ }^{\circ} 14.274$ de 24 de dezembro de 2003, que instituiu a reserva de $10 \%$ das vagas para negros em todos os concursos públicos no Estado do Paraná. O percurso analítico da autora buscou analisar, primordialmente, por meio de método qualitativo, o impacto que trouxe a Lei $\mathrm{n}$. 14.274/2003. Desta forma, concluiu que, em razão de uma democracia racial, ainda há a invisibilidade da população negra nesse setor.

A relevância do estudo apresentando por Souza (2010) está no fato de que o Estado do Paraná foi o primeiro estado do país a realizar um programa de cunho inclusivo, isto é, uma ação afirmativa em relação aos afrodescendentes e o serviço público brasileiro. Verifica-se, ainda, que esta Lei $n^{\circ} 14.274$ de 2003 antecedeu a Lei ${ }^{\circ} 12.990 / 2014$, que prevê as cotas raciais em concursos público federais, sendo esta última publicada após 11 anos da vigência da lei paranaense.

A autora efetuou levantamento do impacto real da Lei, investigando o número de candidatos inscritos e aprovados nos concursos públicos estadual do Paraná. Segundo Souza (2010, p. 23), fazia-se necessária a análise da construção, consolidação e aplicação do que se entendia "ser a primeira "política pública" específica, criada e focalizada para a população negra na história do Estado do Paraná”. A autora pôde concluir que a Lei ${ }^{\circ}$ 14. 274 tratava-se de uma medida de caráter paliativo de promoção de oportunidade e de igualdades.

Conforme Souza (2010, p. 24), as cotas fixas configuram-se como medidas de caráter paliativo, cuja finalidade é a promoção de igualdade para grupos em desvantagens. Essas medidas são justas e legítimas, funcionam como forma de reparação pelas injustiças históricas praticadas contra a população negra, no que tange à escravização e as desigualdades sociorraciais já comprovadas ao longo da história, nascidas de práticas de racismo (indireto ou não) e de discriminação racial. Souza (2010) ainda traz em seu texto uma síntese histórica das ações afirmativas em outros países, como Índia, Estados Unidos, 
África do Sul, bem como apresenta um quadro da desigualdade racial no trabalho do Estado do Paraná, além de uma discussão sobre as ações afirmativas para o trabalho no Brasil.

Apesar de a Lei n ${ }^{\circ} 14.274$ ter sido publicada no estado do Paraná em 2003, possui total relação com o objeto de estudo da Lei n. ${ }^{\circ}$ 12.990/2014, uma vez que ambas possuem um fator comum, constituem-se como ações afirmativas que visam à inclusão do negro no serviço público. O único foco diferenciador é o âmbito de atendimento, ou seja, a Lei $n^{\circ} 14.274$ de 2003 é de competência estadual e a Lei nº 12.990 de 2014 é de competência federal.

\section{CONSIDERAÇÕES FINAIS}

No que concerne ao "estado do conhecimento", vinculado à síntese inventariante das dissertações, foram avaliadas pesquisas dentro do recorte temporal de 2010 a 2016. Para tanto, foram utilizados os bancos de dados da CAPES/IBICT. A pesquisa guiou-se pelos descritores: ações afirmativas; cotas raciais; concurso público/mercado de trabalho. Todas apontaram a ausência de material especificamente relacionado ao corpus eleito e a temática arrolada.

Em parte, é possível justificar a ausência de teses e de dissertações sobre a Lei ${ }^{\circ}$ 12.990 em decorrência da sua publicação ser datada de junho de 2014, o que a configura como um tema atual. Constatou-se, pelo levantamento bibliográfico, que os temas são correlatos no que se refere às ações afirmativas e cotas raciais de inclusão nas universidades públicas e suas fundamentações teóricas, mas nenhum versa especificamente sobre a questão legal eleita.

Os dados coletados no estado do conhecimento sobre o tema indicam que os pesquisadores da área de Educação e Direito sentem-se inquietos e instigados a pesquisar as políticas públicas/ações afirmativas que visam à inclusão dos afrodescendentes nas universidades públicas brasileiras. Constatou-se ainda um número considerável de dissertações e de teses que avaliam as cotas étnico-raciais nas várias universidades públicas do país, demonstrando uma considerável preocupação quanto às leis de inclusão racial, principalmente no que concerne a sua aplicabilidade e resultados obtidos por meio de sua efetivação. 
No levantamento efetuado, observou-se que, dentre as dissertações e teses, existe somente um estudo que analisa cotas para negros nos serviços públicos federais. Isto é, a tese de Marcilene Garcia de Souza (SOUZA, 2003), que analisou as cotas para o ingresso de negros na Administração Pública do Estado do Paraná.

Faz-se necessário salientar que o surgimento da Lei $\mathrm{n}^{\circ} 12.990$ (cotas raciais) ocorreu no ano de 2014. Portanto, é possível que não haja até o momento pesquisado em 2016, teses e dissertações a respeito do assunto. Por isso, as dissertações e teses levantadas apontaram apenas uma correlação com o tema, visto que suas defesas ocorreram com maior intensidade no ano de 2011 e 2012, ou seja, antes da vigência da Lei n $^{\circ} 12.990$ / 2014 (BRASIL, 2014).

Assim, pode-se concluir que o objeto de estudo é um tema recente e relevante para sociedade e para academia, pois busca colocar em debate as questões raciais por meio de análise de políticas públicas inclusivas e que apesar de inseridas no ordenamento jurídico brasileiro muitas vezes não são efetivadas. Já se passaram sete anos da publicação da Lei n. 12.990 de 2014 e pode observar que existem poucos estudos direcionados a análise de cotas raciais em concursos públicos federais direcionados para docentes nas universidades públicas brasileiras.

Verifica-se pelos dados estatísticos IBGE, SIGAP, PEP, IPEA, que a população negra apesar de ser a maioria da população brasileira ainda é flagrante as diferenciações entre a população branca que ocupa a maioria dos cargos hierarquicamente superiores na administração pública federal em detrimento de uma minoria negra que ocupam cargos superiores nos serviços públicos.

Desta maneira, é fundamental abordar nas pesquisas temas relacionados à inserção de negros e negros nos serviços públicos federais para que através desses levantamentos e estudos coloquem em pauta questões de suma importância para que ocorra a inclusão desse grupo excluído nos serviços públicos federais.

\section{REFERÊNCIAS}

ALMEIDA, Daniela Silva da Conceição; SANTOS, Figueroa dos. Representações sociais de estudantes negros: universidade trabalho. 180 p. Dissertação (Mestrado Acadêmico em Psicologia) - Universidade Federal de São Carlos, São Carlos, 2012. 
BEGALLI, Ana Silvia Marcatto. A efetivação do direito ao trabalho da pessoa com deficiência no Brasil: o papel do estado e das empresas. $150 \mathrm{f}$. Dissertação (Mestrado Acadêmico em Direito) - Faculdade de Direito do Sul de Minas, Pouso Alegre, 2012.

BELLO, Luciane. Política de ações afirmativas na UFRGS: o processo de resiliência na trajetória de vida de estudantes cotistas negros com bom desempenho acadêmico. 143 f. Dissertação (Mestrado acadêmico em Educação) - Universidade Federal do Rio Grande do Sul, Porto Alegre, 2011.

BRASIL. Constituição da República Federativa do Brasil. Brasília: Senado Federal, 1988.

BRASIL. Lei ${ }^{\circ} 12.288$ de 20 de Julho de 2010. O Estatuto da Igualdade Racial. Disponível em: < http://www.planalto.gov.br/ccivil/leis/L12288.htm>. Acesso em: 20 de out. de 2021.

BRASIL. Lei $\mathrm{n}^{\circ}$ 12.990, de 9 de junho de 2014. Reserva $20 \%$ das vagas oferecidas em concursos públicos. Diário Oficial da União, Brasília, DF, nº 109, p. 2 e 3, 10 de jun. de 2021.

BRASIL. Lei $\mathrm{n}^{\circ} 14.274$ de 24 de dezembro de 2003. Reserva de vagas aos Afrodescendentes. Palácio do Governo em Curitiba. Publicado no Diário Oficial $\mathrm{n}^{\circ}$ 6634 de 26/12/2003.

BRASIL. Ministério do Planejamento. Painel Estatístico de Servidores Públicos Federais - PEP. Disponível em:

$<\mathrm{http}$ ///www.planejamento.gov.br/noticias/planejamento-lanca-o-painel-estatistico-depessoal>. Acesso em: 03 de jul. de 2021.

BRASIL. Ministério do Planejamento, Desenvolvimento e Gestão Secretária de Gestão de Pessoas e Relações do Trabalho no Serviço Público. Orientação Normativa n. 03 de 1 de agosto de 2016. Disponível em: <http://www.in.gov.br/materia//asset_publisher/Kujrw0TZC2Mb/content/id/23376081/do1-2016-08-02-orientacaonormativa-n-3-de-1-de-agosto-de-2016-23375906>. Acesso em: 1 de mar. de 2018.

BRASIL. Ministério do Planejamento. Sistema Integrado de Administração de Recursos Humanos (SIAPE). Disponível em: <http://www.siapnet.gov.br>. Acesso em: 12 maio de 2017.

BRASIL . Ministério dos Direitos Humanos. Secretária de Promoção de Políticas da Igualdade Racial (SEPPIR). Disponível em: <http://www.seppir.gov.br/>. Acesso em: 12 de jan. de 2016.

BRASIL. Instituto Brasileiro de Informação em Ciência e Tecnologia (IBCTI). Disponível em: <http://www.ibict.br/>acesso em: 10 de maio de 2021.

BRASIL. Instituto Brasileiro de Geografia e Estatística (IBGE). Disponível em: <http://www.ibge.gov.br/home/>. Acesso em: 10 mar. 2017.

BRASIL. Coordenação de Aperfeiçoamento de Pessoa de Nível Superior (CAPES). Disponível em: <http://bancodeteses.capes.gov.br/>. Acesso em: 10 mar. de 2017. 
BRITTO, Thays Oliveira de. Ações afirmativas: cotas para negros nas universidades públicas. 163 p. Dissertação (Mestrado acadêmico em Direito) - Universidade Católica de Pernambuco, Recife, 2011.

Recebido em: 01/10/2021

Aprovado em: 01/11/2021

Publicado em: 10/11/2021 